\title{
The Year of the Seafarer and the impacts of piracy
}

\author{
Efthimios E. Mitropoulos
}

Published online: 10 March 2011

(C) World Maritime University 2011

When the decision was taken to name 2010 as "The Year of the Seafarer", everyone concerned was keen to ensure that the end result would be something tangible. Words, while important and not to be underestimated, would not be sufficient to meet the objectives we had set ourselves - which is why, at the beginning of 2010, I expressed the hope that when, at the end of the year, we would take stock of what we had been able to achieve in its course to improve the life of seafarers, we could be able to say that 2010 did, indeed, make a difference.

During the course of the year, in the context of our overall theme, we pursued three main objectives:

1. To increase awareness among the general public of the indispensable services seafarers render to international seaborne trade, the world economy, and society at large;

2. To send to seafarers a clear message that we recognize and appreciate their services, that we understand the extraordinary conditions and circumstances of their profession, that we do care about them, and that we do all that we can to look after and protect them when the circumstances of their life at sea so warrant; and

3. To redouble our efforts at the regulatory level to create a better, safer, and more secure world in which seafarers can operate.

With regard to the first of these, it was most encouraging to see how many governments, international organizations, and industry bodies took the spirit of the event to heart and provided opportunities for publicizing the Year of the Seafarer. A wide range of activities took place throughout 2010 that added valuable impetus to our traditional World Maritime Day celebration, held at International Maritime Organization's (IMO) London Headquarters in September, and to the Parallel Event held 2 weeks later in Buenos Aires.

E. E. Mitropoulos $(\bowtie)$

Secretary-General, International Maritime Organization, 4 Albert Embankment, London SE1 7SR, UK e-mail: info@imo.org 
Aside from what IMO was able to achieve directly in this regard, a great deal was done through galvanizing others to increase awareness of seafarers and their all-toooften overlooked role in serving, daily, the citizens of the world. It has been a great source of satisfaction to see just how widely the theme has resonated, as manifested in the many conferences, seminars, workshops, award schemes and the like that were organized with the active engagement or symbolic support of our many different partners in the shipping and maritime communities, all focusing on seafarers and the vital work they undertake to the benefit of us all.

I am well aware that the hardships faced by seafarers today cannot be solved by a publicity campaign alone and that we still need to do more to inform the general public. But, I am hopeful that those who create, or perpetuate, the poor conditions under which some seafarers are forced to live and work will find it increasingly difficult to escape the glare of the spotlight that, prompted by the Year of the Seafarer, is now being shone upon them.

Turning to the second objective, that of sending seafarers a clear message of recognition of, and appreciation for, their services, much was done to achieve this when the 2010 Manila Conference unanimously adopted a resolution entitled "Year of the Seafarer", which expressed deep appreciation and gratitude to seafarers from all over the world for their unique contribution to international seaborne trade, the world economy, and society as a whole.

Another highlight of the Manila Conference was its decision to declare the day on which it adopted the comprehensive amendments to the 1995 Convention on Standards of Training, Certification and Watchkeeping for Seafarers (STCW) and STCW Code, the 25th of June, as the annual "Day of the Seafarer", which will be celebrated for the first time this year - an event that, I hope, will maintain our efforts to raise awareness among the general public of the key role played by seafarers in today's world.

On a more personal note, I tried, whenever possible, throughout 2010, to visit seafarer training establishments to meet and talk with seafarers and cadets and to convey to them, directly and personally, our message of appreciation and care for them. I was particularly pleased to be able to join cadets aboard the Polish training ship Dar Mlodziezy for a short but memorable voyage in the Mediterranean and to have the privilege of visiting and offering support to the spouses and families of Filipino seafarers held hostage by pirates off the coast of Somalia.

Also in 2010, we sent a letter to the seafarers of the world, advising them of the objectives of the theme for the year and IMO's aim to pay tribute to them and continued to promote the work of the Organization on matters of related concern, such as the fair treatment of seafarers, their abandonment in foreign ports, denial of their shore leave, and their vulnerability to pirate attacks.

As far as our third objective for the year was concerned (to take action, at the regulatory level, to enhance seafarers' safety and security), I think we have reason to feel satisfied. From the regulatory perspective, the highlight of the Year of the Seafarer was the adoption, by the aforementioned Manila Conference, of historic amendments to the STCW Convention and Code. Collectively known as the Manila Amendments, these will set the international benchmark for the training and education of seafarers for many years to come.

The fact that the Manila Amendments were adopted by consensus, and without a single reservation, along with 17 associated resolutions, is not only a tribute to IMO 
members' dedicated and intensive preparatory work but also an excellent reminder to the outside world that IMO continues to place the human element at the forefront of our legislative work.

As mentioned above, one of today's key concerns for seafarers, their families, and the international maritime community is the issue of piracy. Piracy has, for too long, been a thorny issue for IMO and the maritime community as a whole, with seafarers always bearing the brunt of it. And so, it was with seafarers in mind that the IMO Council decided that the 2011 World Maritime Day theme should be "Piracy: orchestrating the response", with the aim of encouraging a decisive and effective response to the scourge that is modern-day piracy.

IMO has been dealing with piracy issues for the last 30 years. In the early 1980s, it was the Gulf of Guinea that first attracted our attention, while in the late 1990s, and the early part of this century, the focus was on the then hot spots of the South China Sea and the Straits of Malacca and Singapore. Through a series of measures, developed and implemented by, and with the cooperation and support of, the littoral States, States using the Straits and the industry, we have been able to help significantly reduce piracy in those parts of the world.

However, the problem has lately manifested itself in other regions, most notablybut not exclusively — off the coast of Somalia, in the Gulf of Aden, and the wider Indian Ocean. We believe that we can use the experience gained and the successes achieved by IMO in reducing piracy elsewhere to good effect here, too, but to do so requires an orchestrated and coordinated response.

We have, therefore, developed an action plan to maintain and, indeed, strengthen our focus on anti-piracy endeavors of all kinds and to facilitate a broader, global effort. We have identified six prime objectives that we hope all stakeholders will espouse during 2011, and beyond, if necessary. These objectives are:

1. To increase pressure at the political level to secure the release of all hostages being held by pirates;

2. To review and improve the IMO guidelines to Administrations and seafarers and promote compliance with industry best management practice and the recommended preventive, evasive, and defensive measures ships should follow;

3. To promote greater levels of support from, and coordination with, navies;

4. To promote anti-piracy coordination and cooperation procedures between and among States, regions, organizations, and industry;

5. To assist states to build capacity in piracy-infested regions of the world, and elsewhere, to deter, interdict, and bring to justice those who commit acts of piracy and armed robbery against ships; and

6. To provide care, during the post-traumatic period, for those attacked or hijacked by pirates and for their families.

Let me now put some flesh on these bones. Underlying all our efforts to achieve these objectives will be the need to engage at the political level to bring about a solution to the Somali problem and thus facilitate and expedite the release of the seafarers and others held hostage. Calling the world's attention to the unacceptable plight of the innocent victims of pirates can help to create the momentum necessary for action to be taken to hasten their release. 
In the meantime, there should be no respite in our efforts to strengthen the protection of persons, ships, and cargoes in piracy-infested areas (at the same time preserving the integrity of shipping lanes of strategic importance and significance, such as the Gulf of Aden) through rigorous implementation of the International Safety Management Code and the International Ships and Port Facility Code; improvements to the accessibility and distribution of IMO guidelines and industry best management practice guidance; ensuring that ships' crews are aware of how to access the available naval protection, and that they are advised how to best implement the preventive, evasive, and defensive measures recommended by IMO and the industry; and, at the same time, promoting even greater levels of coordination among navies, above and beyond the unprecedented degree of cooperation that has already characterized the international naval response.

During 2011, we intend to promote further cooperation between and among States, regions, and organizations in reducing the risk of attacks on ships through information sharing, coordination of military and civil efforts, and development and implementation of regional initiatives, such as the IMO-led Djibouti Code of Conduct.

We will also look to help build the capacity of States, in affected regions of the world and elsewhere, to deter, interdict, and bring to justice those who commit acts of piracy and armed robbery against ships, thereby enhancing maritime law enforcement and the safety of life at sea. This will, we believe, also help tackle the root causes of piracy, through the provision of assistance to States for the development of their maritime law enforcement capacities and the protection of their maritime resources.

Specifically, in the case of Somalia, we intend to contribute, in any way possible (including through the establishment of a coastal monitoring and law enforcement force) to its moving to a state of stability that will, in due course, have a beneficial impact on the overall situation.

And we will work with Governments and the industry to ensure that released seafarers and their families receive care during the post-traumatic period.

There is already good progress on which to build. Through the Djibouti Code of Conduct, for example, we are establishing information-sharing centers in Yemen, Kenya, and the United Republic of Tanzania, as well as a regional training center in Djibouti. In partnership with the United Nations Office on Drugs and Crime, we are helping to develop the legal framework necessary to prosecute pirates. We will continue to give this initiative the highest priority, with the aim of assisting States in the region to build and develop their own, effective counter-piracy infrastructure and operations.

However, as the statistics so bleakly indicate, piracy and armed robbery against ships remain real and ever-present dangers to those who use the seas for peaceful purposes - and, as long as pirates continue harassing shipping, endangering the critical delivery of humanitarian aid, and hijacking ships and seafarers, we are neither proud of, nor content with, the results achieved so far. This year, we are resolved to redouble our efforts and, in so doing, generate a broader, global response to modern-day piracy. More needs to be done, including the imposition of sanctions on the proceeds derived from hijacked ships, if the ultimate goal of consigning piracy to the realms of history is to be achieved. We hope that our choice of the 
theme for 2011 will provide an appropriate rallying point around which all those who can make a difference can focus their efforts.

Although piracy manifests itself at sea, the root of the problem is to be found ashore. It is a complex issue but, in essence, piracy is a criminal offense, driven by economic conditions and allowed to flourish in the absence of effective law enforcement. A sustainable solution is the goal, and this requires the establishment not only of effective governance but also the rule of law, reliable security agencies, and alternative employment opportunities for the Somali people.

The threat at sea is related directly to the situation ashore, and the only truly effective way to manage this crisis in the long term is to address governance and security issues within Somalia itself. This has been an important priority for the United Nations as a whole and will continue to be so during 2011.

On World Maritime Day 2010, I received almost one million signatures of a petition calling for an immediate end to piracy. As I remarked on the occasion, I sincerely hope that the strength of feeling expressed by so many people, from so many countries, will help to sensitize both Governments and the wider public to the harm being caused by piracy, as well as to exert pressure on those who need to act, to do so, in the interest of achieving a satisfactory resolution of this unacceptable situation. 